\title{
Hubungan Wilayah Tempat Tinggal dengan Pemberian ASI Ekslusif pada Anak 0-5 Bulan di Indonesia (Analisis Data Survei Demografi Kesehatan Indonesia) Tahun 2017
}

\author{
The Association between Residence and Exclusive Breastfeeding Practice \\ among Infant 0-5 Months in Indonesia (Indonesian Demographic Health \\ Survey Data Analysis) in 2017
}

\author{
Andi Karnila ${ }^{a^{*}}$, Krisnawati Bantas ${ }^{a}$
}

\footnotetext{
$a^{a^{*}}$ Program Studi Magister Epidemiologi, Fakultas Kesehatan Masyarakat Universitas Indonesia, Depok 16424, Indonesia

${ }^{\text {b }}$ Departemen Epidemiologi, Fakultas Kesehatan Masyarakat Universitas Indonesia, Lantai 1 Gedung A, Kampus UI Depok, Indonesia
}

\section{A B S T R A K}

ASI ekslusif dapat mencegah morbiditas dan mortalitas pada anak. Wilayah tempat tinggal perkotaan dan pedesaan memiliki keterkaitan dengan praktek pemberian ASI ekslusif. Penelitian ini bertujuan untuk menganalisis hubungan antara wilayah tempat tinggal dengan praktek pemberian ASI ekslusif pada anak 0-5 bulan di Indonesia. Desain studi penelitian yaitu cross sectional menggunakan data sekunder Survei Demografi Kesehatan Indonesia. Penelitian ini dilaksanakan diseluruh provinsi di Indonesia. Variabel dalam penelitian ini terdiri dari ASI ekslusif sebagai variabel dependen, wilayah tempat tinggal sebagai variabel independen dan variabel perancu yang terdiri dari umur ibu, pendidikan ibu, paritas, kondisi depresi ibu, status bekerja, status ekonomi, status pernikahan, inisiasi menyusui dini, jenis persalinan, tempat bersalin, antenatal care dan berat lahir anak. Teknik sampling menggunakan total sampling dengan jumlah sampel 1.266. SPSS 16 digunakan sebagai software statistik pada penelitian. Data dianalisis menggunakan regresi logistik dan prevalence odds ratio. Hasil penelitian menunjukkan prevalensi ASI ekslusif 67,1\% dan $37,9 \%$ tidak ASI ekslusif. Prevalensi wilayah tempat tinggal pedesaan $53,5 \%$ dan perkotaan $46,5 \%$. Terdapat hubungan wilayah tempat tinggal dengan pemberian ASI ekslusif POR 1,298 (95\%Cl 1,023 - 1,646). Ibu yang tinggal diperkotaan memiliki peluang yang lebih tinggi untuk tidak memberikan ASI ekslusif dibandingkan ibu yang tinggal dipedesaan, setelah dikontrol dengan variabel status bekerja, inisiasi menyusui dini dan status pernikahan.

Kata kunci: ASI ekslusif, Wilayah tempat tinggal, SDKI, Indonesia

\section{A B STRAC T}

Exclusive breastfeeding can prevent morbidity and mortality among young children. Rural and urban residential areas are related to exclusive breastfeeding practices. The aim of the study was to analyze the association between residence and exclusive breastfeeding among infant $0-5$ months in Indonesia. This is a cross sectional study using secondary data of Indonesia Demographic Health Survey (IDHS). This study was conducted in all province of Indonesia. Variables included in this study were exclusive breastfeeding as dependent variable, residence as independent variable and potential confounder variables including mother's age, mother's education, parity, mother's depression, working status, economic status, marital status, early breastfeeding initiation, mode of delivery, place of delivery, antenatal care and infant birth weight. Total sampling was used and the sample size was 1.266. SPSS 16 was used as statistic software in this study. Data were analyzed by logistic regression and prevalence odds ratio. The results showed prevalence of exclusive breastfeeding was $67.1 \%$ and non exclusive breastfeeding was $37,9 \%$. Prevalence of rural and urban areas was 53,5\% and $46,5 \%$. There was an association between residence and exclusive breastfeeding POR 1.298 (95\% Cl $1.023-1.646)$. Mother who living in urban had a 1.2 times higher risk of non exclusive breastfeeding than mother who living in rural after being controlled by working status, early breastfeeding initiation and marital status variables.

Keywords: Exclusive breastfeeding, Residence, , IDHS, Indonesia

\section{Pendahuluan}

WHO mendefinisikan ASI ekslusif yaitu pemberian ASI saja, tidak ada cairan atau padatan lain yang diberikan bahkan air terkecuali larutan tetes/ sirup vitamin, mineral atau obat obatan. Menyusui secara eksklusif direkomendasikan hingga anak berusia 6 bulan, dengan pemberian ASI berkelanjutan bersama dengan makanan pendamping yang sesuai hingga usia dua tahun atau lebih. ${ }^{1}$ Tidak ASI ekslusif merupakan faktor risiko morbiditas dan mortalitas bayi dan anak yang diperparah oleh pemberian makanan pendamping ASI yang tidak tepat. Dampak jangka panjang berkurangnya produktivitas, dan gangguan perkembangan intelektual dan sosial. ${ }^{2}$ ASI ekslusif dapat mengurangi terjadinya penyakit pada masa kanakkanak seperti diare dan pneumonia serta dapat pemulihan lebih cepat saat sakit. ${ }^{3}$ Bagi ibu, menyusui terbukti melindungi terhadap perdarahan postpartum, kanker ovarium dan payudara, penyakit jantung dan diabetes tipe 2.4 Pada tahun 2016 pemberian ASI ekslusif kurang dari 40\%. ${ }^{5}$ Di Indonesia berdasarkan 
hasil SDKI 2007 dan 2012, pemberian ASI ekslusif sebesar $32,4 \%^{6}$, dan $41 \%{ }^{7}$

Wilayah tempat tinggal berkontribusi dalam proses pemberian ASI ekslusif. Ibu yang tinggal di perkotaan memiliki peluang lebih kecil untuk memberikan ASI ekslusif dibandingkan dipedesaan. ${ }^{8}$ Hal ini dapat terjadi dikarenakan akses dan ketersediaan susu formula diwilayah perkotaan lebih mudah dibandingkan wilayah pedesaan. Selain itu, ketersediaan susu formula tersebut, turut mendorong ibu dengan ketidak cukupan ASI untuk memilih memberikan susu formula sebagai tambahan. ${ }^{9}$

Selain faktor wilayah tempat tinggal, terdapat faktor lain yang dikaitkan dengan pemberian ASI ekslusif. Beberapa penelitian membuktikan adanya faktor-faktor lain yang berhubungan dengan pemberian ASI ekslusif. Secara umum faktor yang ditemukan berhubungan dengan pemberian ASI ekslusif diantaranya umur ibu, pendidikan ibu, pekerjaan, jenis persalinan, paritas, status ekonomi, kondisi depresi, dan inisiasi menyusui dini. ${ }^{10,11,12}$

Tujuan penelitian untuk mengetahui hubungan wilayah tempat tinggal dengan pemberian ASI ekslusif pada anak 0-5 bulan berdasarkan analisis data Survei Demografi Kesehatan Indonesia tahun 2017.

\section{Metode Penelitian}

Data penelitian ini merupakan data Survei Demografi Kesehatan Indonesia tahun 2017. Populasi penelitian adalah wanita usia subur (WUS) 15-49 tahun di Indonesia. Sampel penelitian adalah WUS, memiliki anak usia 0-5 bulan, merupakan anak terakhir, tidak kembar, masih hidup dan masih menyusui. Data yang tidak lengkap tidak dimasukkan dalam sampel penelitian. Dengan menggunakan total sampling diperoleh jumlah sampel 1.266 yang memenuhi kriteria. Semua sample diwawancarai menggunakan kuesioner terstruktur SDKI 2017.

Variabel yang dikumpulkan terdiri dari variabel ASI ekslusif, wilayah tempat tinggal, kondisi depresi, umur, pendidikan, inisiasi menyusui dini, paritas, status bekerja, status ekonomi, berat lahir anak, jenis persalinan, status pernikahan, tempat bersalin dan kunjungan antenatal care. Variabel dependen pemberian ASI ekslusif diukur berdasarkan apakah anak mengkonsumsi minuman atau makanan dalam kurun waktu 24 jam sebelum survei dilaksanakan. Selanjutnya variabel independen wilayah tempat tinggal diukur berdasarkan jawaban responden mengenai wilayah tempat tinggal saat ini.

Data dianalisis menggunakan SPSS versi 16. Analisis yang digunakan yaitu univariat, bivariat dan multivariat. Analisis univariat bertujuan memperoleh distribusi frekuensi variabel penelitian. Analisis Bivariat bertujuan untuk seleksi kandidat dalam model analisis multivariat menggunakan uji logistik regresi. Analsis multivariat bertujuan untuk melihan hubungan variabel wilayah tempat tinggal dengan pemberian ASI ekslusif dengan mengontrol variabel lainnya.

Sampel yang diperoleh tidak melalui proses pembobotan dikarenakan kriteria sampel lebih spesifik merujuk pada WUS yang memiliki anak usia 0-5 bulan. Pada pengolahan data dilakukan seleksi sesuai kriteria sampel penelitian. Kemudian dilakukan coding pada masing-masing variabel. Proses pengcodingan pada setiap variabel dibagi menjadi dua yaitu coding 0 (tidak berisiko) dan coding 1 (berisiko). Dalam hal ini, untuk variabel dependen coding 0 (ASI ekslusif) dan coding 1 (tidak ASI ekslusif). Hal ini juga disesuaikan dengan variabel-variabel lainnya.

Standar prosedur dan kuesioner Demograpic and Health Survey (DHS) telah melalui proses peninjauan dan persetujuan oleh ICF Institutional Review Board (IRB). Protokol survei negara khusus DHS telah ditinjau oleh ICF-IRB dan juga IRB dinegara tersebut. ICF-IRB memastikan bahwa survei yang dilakukan mematuhi U.S. Department of Health and Human Services regulations untuk perlindungan subyek manusia (45 CFR 46). IRB memastikan bahwa survei yang dilakukan setiap negara mematuhi norma dan perundang-undangan yang berlaku di negara tersebut. Selain itu, data SDKI 2017 yang digunakan dalam penelitian ini telah mendapatkan persetujuan dan perizinan penggunaan data dari Badan Kependudukan dan Keluarga Berencana Nasional (BKKBN) dengan nomor surat 586/LB.01/H3/2019.

\section{Hasil}

Tabel 1 menunjukkan distribusi karakteristik variabel penelitian. Hasil tersebut menunjukkan bahwa dari jumlah sampel 1.266 responden yang memiliki anak usia 0-5 bulan, terdapat 849 (67,1\%) memberikan ASI ekslusif pada anaknya dan 417 (37,9\%) tidak memberikan ASI ekslusif. Mayoritas responden bertempat tinggal diwilayah pedesaan (53,5\%). Mayoritas responden berumur 25-29 tahun (29,4\%). Pendidikan terbanyak yang ditamatkan responden yaitu tingkat SMP (57,6\%). Jumlah anak yang dilahirkan (paritas) <2 (70,5\%). Responden yang mengalami depresi postpartum (10,2\%). Responden yang bekerja (41,9\%), status ekonomi terbanyak yaitu pada kategori rendah $(46,4 \%)$ dan responden yang menikah $(98,4 \%)$. Selanjutnya untuk waktu inisiasi menyusui dini $\leq 1$ jam (61,8\%). Mayoritas responden melakukan persalinan secara normal (82,2\%). Tempat bersalin terbanyak dilakukan di fasilitas pemerintah (43,7\%). Kemudian untuk kunjungan ANC $\geq 8$ kali (54,3\%). Mayoritas berat lahir anak $\leq 2500$ gram $(95,2 \%)$. 
Karnila \& Bantas. Hubungan Wilayah Tempat Tinggal dengan Pemberian ASI Ekslusif Pada Anak 0-5 Bulan di Indonesia

Tabel 1. Distribusi Karakteristik Variabel Penelitian

\begin{tabular}{|c|c|c|}
\hline Variabel & $n$ & $\%$ \\
\hline \multicolumn{3}{|l|}{ ASI Ekslusif } \\
\hline Tidak ASI Ekslusif & 417 & 37,9 \\
\hline ASI Ekslusif & 849 & 67,1 \\
\hline \multicolumn{3}{|l|}{ Tempat Tinggal } \\
\hline Pedesaan & 677 & 53,5 \\
\hline Perkotaan & 589 & 46,5 \\
\hline \multicolumn{3}{|l|}{ Umur Ibu } \\
\hline$\leq 24$ Tahun & 331 & 26,1 \\
\hline 25-29 Tahun & 372 & 29,4 \\
\hline 30-33 Tahun & 270 & 21,3 \\
\hline > 33 Tahun & 293 & 23,1 \\
\hline \multicolumn{3}{|l|}{ Pendidikan Ibu } \\
\hline SD & 281 & 22,2 \\
\hline SMP & 729 & 57,6 \\
\hline SMA & 256 & 20,2 \\
\hline \multicolumn{3}{|l|}{ Paritas } \\
\hline$<2$ Anak & 893 & 70,5 \\
\hline$\geq 2$ Anak & 373 & 29,5 \\
\hline \multicolumn{3}{|l|}{ Depresi } \\
\hline Depresi & 129 & 10,2 \\
\hline Tidak Depresi & 1137 & 89,9 \\
\hline \multicolumn{3}{|l|}{ Status Bekerja } \\
\hline Bekerja & 530 & 41,9 \\
\hline Tidak Bekerja & 736 & 58,1 \\
\hline \multicolumn{3}{|l|}{ Status Pernikahan } \\
\hline Tidak menikah & 20 & 1,6 \\
\hline Menikah & 1246 & 98,4 \\
\hline \multicolumn{3}{|l|}{ Inisiasi Menyusui Dini } \\
\hline$>1$ jam & 483 & 38,2 \\
\hline$\leq 1 \mathrm{jam}$ & 783 & 61,8 \\
\hline \multicolumn{3}{|l|}{ Jenis Persalinan } \\
\hline Sesar & 225 & 17,8 \\
\hline Normal & 1041 & 82,2 \\
\hline \multicolumn{3}{|l|}{ Status Ekonomi } \\
\hline Rendah & 588 & 46,4 \\
\hline Menengah & 267 & 21,1 \\
\hline Tinggi & 411 & 32,5 \\
\hline \multicolumn{3}{|l|}{ Tempat Bersalin } \\
\hline Rumah & 228 & 18,0 \\
\hline Sektor Swasta & 485 & 38,3 \\
\hline Sektor pemerintah & 553 & 43,7 \\
\hline \multicolumn{3}{|l|}{ Kunjungan ANC } \\
\hline$<8$ kali & 579 & 45,7 \\
\hline$\geq 8$ kali & 687 & 54,3 \\
\hline \multicolumn{3}{|l|}{ Berat Lahir Anak } \\
\hline$<2500$ gram & 61 & 4,8 \\
\hline$\geq 2500$ gram & 1205 & 95,2 \\
\hline
\end{tabular}

Tabel 2 menunjukkan distribusi pemberian ASI ekslusif berdasarkan setiap variabel dan hubungan antara variabel-variabel tersebut dengan pemberian ASI ekslusif. Dari 13 variabel pada analisis hubungan pemberian ASI ekslusif diperoleh beberapa variabel yang berhubungan secara statistik dengan nilai $p<0,05$. Variabel tersebut yaitu variabel wilayah tempat tinggal, status bekerja, status pernikahan, inisiasi menyusui dini (IMD). Namun untuk masuk dalam analisis multivariat, variabel yang memiliki nilai $p<0,25$ juga diperhitungkan dan dimasukkan dalam analisis. Sehingga variabelvariabel yang dapat masuk dalam kandidat multivariat yaitu variabel wilayah tempat tinggal, umur, depresi, paritas, status bekerja, paritas, inisiasi menyusui dini, status pernikahan dan jenis persalinan. Pada analisis multivariat, dilakukan uji interaksi dan uji confounding. Sehingga diperoleh model akhir multivariat yang mengikutsertakan variabel wilayah tempat tinggal, status bekerja, inisiasi menyusui dini dan status pernikahan.
Tabel 2. Analisis Bivariat Hubungan Variabel Independen Utama dan Variabel Kovariat Dengan Pemberian ASI Ekslusif Analisis Data SDKI Tahun 2017

\begin{tabular}{|c|c|c|c|c|c|c|c|}
\hline \multirow{3}{*}{ Variabel } & \multicolumn{4}{|c|}{ ASl Ekslusif } & \multirow{3}{*}{ POR } & \multirow{3}{*}{ व95\% } & \multirow{3}{*}{$\begin{array}{c}p- \\
\text { value }\end{array}$} \\
\hline & \multicolumn{2}{|c|}{ TidakASI Ekslusif } & \multicolumn{2}{|c|}{ ASl Ekslusif } & & & \\
\hline & $n$ & $\%$ & $n$ & $\%$ & & & \\
\hline \multicolumn{8}{|l|}{ Terrpat tinggal } \\
\hline Perkotaan & 213 & 51,1 & 376 & 44,3 & 1,313 & $1,038-1,661$ & $0,023^{*}$ \\
\hline Pedesaan & 204 & 48,9 & 473 & 55,7 & & & \\
\hline \multicolumn{8}{|l|}{ Depresi } \\
\hline Depresi & 36 & 8,6 & 93 & 11,0 & 0,768 & $0,513-1,150$ & 0,200 \\
\hline Tidak depresi & 381 & 91,4 & 756 & 89,0 & & & \\
\hline \multicolumn{8}{|l|}{ Umur } \\
\hline$\leq 24$ Tahun & 112 & 26,9 & 219 & 25,8 & 0,863 & $0,622-1,199$ & 0,381 \\
\hline 25-29Tahun & 109 & 26,1 & 263 & 31,0 & 0,700 & $0,505-0,969$ & 0,031 \\
\hline 30-33 Tahun & 87 & 20,9 & 183 & 21,6 & 0,803 & $0,567-1,137$ & 0,216 \\
\hline$>33$ tahun & 109 & 26,1 & 184 & 21,7 & & & \\
\hline \multicolumn{8}{|l|}{ Pendidikan } \\
\hline SMA & 89 & 21,3 & 167 & 19,7 & 1,095 & $0,765-1,566$ & 0,620 \\
\hline SMP & 236 & 56,6 & 493 & 58,1 & 0,983 & $0,733-1,319$ & 0,911 \\
\hline SD & 92 & 22,1 & 189 & 22,3 & & & \\
\hline \multicolumn{8}{|l|}{ Paritas } \\
\hline$<2$ Anak & 136 & 32,6 & 237 & 27,9 & 1,250 & $0,970-1,611$ & 0,085 \\
\hline$\geq 2$ Anak & 281 & 6,4 & 612 & 72,1 & & & \\
\hline \multicolumn{8}{|l|}{ Status Bekeja } \\
\hline Bekeja & 194 & 46,5 & 336 & 39,6 & 1,328 & $1,048-1,683$ & $0,019^{\star}$ \\
\hline Tidak Bekeja & 223 & 53,5 & 513 & 60,4 & & & \\
\hline \multicolumn{8}{|l|}{ Status Ekonomi } \\
\hline Tinggi & 136 & 32,6 & 275 & 32,4 & 0,997 & $0,763-1,303$ & 0,981 \\
\hline Menengah & 86 & 20,6 & 181 & 21,3 & 0,958 & $0,703-1,304$ & 0,783 \\
\hline Rendah & 195 & 46,8 & 393 & 46,3 & & & \\
\hline \multicolumn{8}{|l|}{ Status Pernikahan } \\
\hline Tidak Menikah & 13 & 3,1 & 7 & 0,8 & 3,871 & $1,533-9,775$ & $0,004^{*}$ \\
\hline Merikah & 404 & 96,9 & 842 & 99,2 & & & \\
\hline \multicolumn{8}{|l|}{ IMD } \\
\hline >1 jam & 184 & 44,1 & 299 & 35,2 & 1,453 & $1,144-1,845$ & $0,002^{*}$ \\
\hline$\leq 1 \mathrm{jam}$ & 233 & 55,9 & 550 & 64,8 & & & \\
\hline \multicolumn{8}{|l|}{ Jenis Persalinan } \\
\hline Sesar & 86 & 20,6 & 139 & 16,4 & 1,327 & $0,984-1,789$ & 0,063 \\
\hline Normal & 331 & 79,4 & 710 & 83,6 & & & \\
\hline \multicolumn{8}{|l|}{ Terrpat Bersalin } \\
\hline Rumah & 75 & 18,0 & 153 & 18,0 & 1,059 & $0,762-1,472$ & 0,734 \\
\hline Sektor Swasta & 16 & 40,0 & 318 & 37,5 & 1,134 & $0,875-1,470$ & 0,341 \\
\hline Sektor Pemerintah & 175 & 42,0 & 378 & 44,5 & & & \\
\hline \multicolumn{8}{|l|}{ Kunjungan ANC } \\
\hline$<8$ kali & 199 & 47,7 & 380 & 44,8 & 1,127 & $0,891-1,425$ & 0,320 \\
\hline$\geq 8$ kali & 218 & 52,3 & 469 & 55,2 & & & \\
\hline \multicolumn{8}{|l|}{ Berat Lahir Anak } \\
\hline$<2500$ & 22 & 5,3 & 39 & 4,6 & 1,157 & $0,677-1,978$ & 0,595 \\
\hline$\geq 2500$ & 395 & 94,7 & 810 & 95,4 & & & \\
\hline
\end{tabular}

Tabel 3. Model Akhir Hubungan Wilayah Tempat Tinggal Dengan Pemberian ASI Ekslusif Analisis Data SDKI Tahun 2017

\begin{tabular}{lccc}
\hline \multicolumn{1}{c}{ Variabel } & POR & C195\% & P value \\
\hline Wilayah tempat tinggal & 1,298 & $1,023-1,646$ & 0,031 \\
Status bekerja & 1,307 & $1,029-1,660$ & 0,028 \\
Inisiasi menyusui dini & 1,425 & $1,119-1,814$ & 0,004 \\
Status pernikahan & 4,174 & $1,633-10,664$ & 0,003 \\
\hline
\end{tabular}

\section{Diskusi}

Nutrisi pada anak usia dini sangat penting, tidak hanya untuk kesehatan anak secara langsung tetapi juga untuk manfaat jangka panjang. ASI ekslusif dapat memberikan perlindungan terhadap penyakit menular seperti gastroenteritis dan penyakit pernapasan serta penyakit kronis lainnya dalam jangka panjang. Karena 
itu WHO merekomendasikan pemberian ASI ekslusif hingga anak berusia 6 bulan serta berkelanjutan hingga 2 tahun atau lebih bersamaan dengan makanan pendamping yang sesuai kebutuhan anak. ${ }^{1}$

Pada penelitian ini diperoleh $67,1 \%$ ibu memberikan ASI ekslusif. Hasil tersebut berdasaran pertanyaan kuesioner mengenai makanan dan minuman selain ASI yang dikonsumsi bayi 0-5 bulan pada waktu 24 jam sebelum wawancara dilaksanakan. Hasil penelitian ini lebih tinggi dibandingkan dengan prevalensi pemberian ASI ekslusif di Indonesia berdasarkan data Kementeri Kesehatan tahun 2017 sebesar 46,74\%. ${ }^{13}$ Namun prevalensi pemberian ASI ekslusif dalam penelitian ini, masih rendah dibandingkan prevalensi pemberian ASI ekslusif diwilayah Gozamin Ethiopia sebesar $74,1 \% .^{14}$

Berdasarkan analisis multivariat diperoleh bahwa wilayah tempat tinggal berhubungan signifikan dengan pemberian ASI ekslusif. Ibu yang memiliki anak usia 0-5 bulan dan tinggal diperkotaan berpeluang lebih besar untuk tidak memberikan ASI ekslusif dbandingkan ibu yang tinggal dipedesan. Penelitian ini sejalan dengan penelitin lainnya yang dilakukan diwilayah Malaysia. Ibu yang bertempat tinggal diwilayah rural berpeluang lebih besar untuk memberikan ASI ekslusif dibandingkan ibu yang tinggal diwilayah urban. ${ }^{15}$ Penelitian yang sama juga dilakukan di Ethiophia, bahwa wilayah tempat tinggal merupakan salah satu prediktor pemberian ASI ekslusif. ${ }^{9}$ Hal ini dikarenakan masyarakat perkotaan memiliki gaya hidup yang modern dibandingkan masyarakat pedesaan. Diwilayah perkotaan, pemberian susu formula merupakan hal yang modern dan lazim dilakukan. Pemberian susu formula dianggap lebih bergengsi dibandingkan pemberian ASI. ${ }^{16}$

Ibu yang tinggal diwilayah perkotaan, cenderung memiliki pendidikan yang tinggi dan status ekonomi yang tinggi. Sehingga hal ini dapat menjadi faktor risiko untuk menghentikan pemberian ASI ekslusif. ${ }^{17}$ Mayoritas ibu yang tinggal diperkotaan bekerja paruh waktu ataupun bekerja seharian. Kondisi tersebut mengakibatkan ibu lebih memilih untuk menggantikan pemberian ASI dengan susu formula. ${ }^{18}$ Hal ini tentunya akan berdampak negatif terhadap pemberian ASI ekslusif. Hasil dari penelitian ini juga membuktikan bahwa ibu yang tinggal diwilayah perkotaan lebih cepat menghentikan pemberian ASI ekslusif dibandingkan ibu yang tinggal diwilayah pedesaan. Penelitian ini tentunya sejalan dengan buktibukti yang diperoleh dari penelitian-penelitian lainnya.

Selain wilayah tempat tinggal, faktor lain yang memiliki keterkaitan dengan ASI ekslusif diantaranya status bekerja, inisiasi menyusui dini dan status pernikahan. Penelitian ini sejalan dengan beberapa penelitian lainnya. Penelitian yang dilakukan oleh
Adugna diwilayah Hawasa Ethiopia dengan jumlah sampel 529 ibu yang memiliki bayi berumur 0-6 bulan. Hasil penelitian Adugna membuktikan bahwa ibu bekerja berpeluang lebih besar untuk tidak ASI ekslusif dibandingkan tidak bekerja. ${ }^{19}$ Ibu yang bekerja juga berhubungan dengan pemberian ASI ekslusif sesuai dengan penelitian Mulusew diwilayah Azezo distrik Ethiopia. ${ }^{20}$

Ibu yang dengan segera melakukan inisiasi menyusui dini berpeluang lebih besar untuk ASI ekslusif dibandingkan dengan yang melakukan inisiasi menyusui dini lebih dari satu jam setelah kelahiran berdasarkan penelitian Lenja diwilayah Offa Ethiopia dengan jumlah sampel 396 ibu yang memiliki anak < 6 bulan. ${ }^{21}$ Penelitian lainnya diwilayah Mecha Ethiopia dengan jumlah sampel 819 ibu, juga memperoeh hasil yang sama mengenai hubungan inisiasi menyusui dini dengan pemberian ASI ekslusif. ${ }^{22}$ Kemudian status pernikahan, ibu yang tidak memiliki pasangan/tidak menikah berpeluang lebih besar untuk tidak ASI ekslusif dibandingkan dengan yang memiliki pasangan sesuai penelitian yang dilakukan diwilayah rural Sorro Ethiopia dengan jumlah sampel 602 ibu. ${ }^{23}$ Penelitian yang serupa juga dilakukan Tampah di Ghana dengan jumlah sampel 316. ${ }^{24}$

Pada penelitian ini terdapat 1.443 sampel yang memenuhi kriteria, akan tetapi yang masuk sebagai sampel penelitian berjumlah 1.266, dikarenakan terdapat 177 sampel yang tidak memiliki data lengkap. Sehingga respon rate dalam penelitian ini sebesar $87,7 \%$. Hasil penelitian ini dapat digeneralisasikan ke populasi eligible dan populasi sumber. Akan tetapi, untuk populasi lain yang relevan masih harus dilihat lagi karakteristiknya. Generalisasi dapat diterapkan pada populasi lain yang relevan bila karakteristik responden mirip atau sama dengan sampel penelitian ini. Penelitian ini memiliki keterbatasan dalam pengukuran ASI ekslusif. ASI ekslusif diukur berdasarkan konsumsi makanan dan minuman bayi usia 0-5 bulan dalam periode waktu 24 jam sebelum survei dilaksanakan. Hal ini dapat menimbulkan bias misklasifikasi dikarenakan hanya memperhitungkan pemberian makanan dan minuman selain ASI dalam waktu 24 jam tanpa mempertimbangkan periode waktu sebelumnya.

\section{Kesimpulan}

Wilayah tempat tinggal berhubungan dengan pemberian ASI ekslusif, POR 1,298 (95\%Cl 1,023 1,646). Ibu yang tinggal diperkotaan memiliki peluang yang lebih besar untuk tidak memberikan ASI ekslusif dibandingkan dengan ibu yang tinggal dipedesaan, setelah dikontrol dengan variabel status bekerja, inisiasi menyusui dini dan status pernikahan. 


\section{Referensi}

1. WHO. Exclusive breastfeeding for optimal growth, development and health of infants. 2019 [cited 2019 Mei 17]; Available from: https://www.who.int/elena/titles/ exclusive_breastfeeding/en/

2. WHO. Global strategy for infant and young child feeding. 2003 [cited Mei 17]; Availablefrom:https:// www. who.int.nutrition/publications/infantfeeding/ 9241562218/en

3. WHO. Maternal, new born, child and adolescent health: breastfeeding. 2019 [cited 2019 Mei 17]; Available from: http://www.who.int/maternal_child_adolescent/en/

4. Choudhury R, Sinha B, Sankar MJ, Taneja S, Bhandari N, Rollins $N$, et al. Breastfeeding and maternal health outcomes/ : a systematic review and meta-analysis. Acta Pædiatrica. 2015;96-113.

5. Hajeebhoy N. The lancet breastfeeding series. 2016 [cited 2019 Mei 17]; Available from: https://.www.thelancet.com/ series/breastfeeding

6. BPS. Indonesia demographic and health survey 2007. 2007 [cited 2019 Mei 13]; Available from: https:// mikrodata.bps.go.id/mikrodata/index.php/catalog/262

7. BPS. Indonesia demographic and health survey 2012. 2012 [cited 2019 Mei 13]; Available from: https:// mikrodata.bps.go.id/mikrodata/index.php/catalog/261

8. Asfaw MM, Argaw MD, Kefene ZK. Factors associated with exclusive breastfeeding practices in Debre Berhan District , Central Ethiopia/ : a cross sectional community based study. Int Breastfeed J [Internet]. 2015 [cited 2019 Mei 13] ;1-9. Available from: http://dx.doi.org/10.1186/s13006015-0049-2

9. Karkee R, Lee AH, Khanal V, Binns CW. A community-based prospective cohort study of exclusive breastfeeding in Central Nepal. BMC Public Health [Internet]. 2014 [cited 2019 Mei 13];1-6. Available from: http:// www.biomedcentral.com/1471-2458/14/927

10. Yeneabat T, Belachew T, Haile M. Determinants of cessation of exclusive breastfeeding in Ankesha Guagusa Woreda, Awi Zone, Northwest Ethiopia/ : a cross-sectional study. BMC Pregnancy Childbirth [Internet]. 2014 [cited 2019 Mei 12];1-12. Available from: http:// www.biomedcentral.com/1471-2393/14/262

11. Silva CS, Lima MC, Oliveira JS, Monteiro JS, Lima NMS, Santos RMAB, et al. Association between postpartum depression and the practice of exclusive breastfeeding in the first three months of life. J Pediatr [Internet]. 2017 [cited 2019 Mei 15] ;93(4):356-64. Available from: http:/ /dx.doi.org/10.1016/j.jped.2016.08.005

12. Noughabi ZS, Tehrani SG, Foroushani AR, Nayeri F, Baheiraei A. Prevalence and factors associated with exclusive breastfeeding at 6 months of life in Tehran/ : a populationbased study. East Mediterr Heal J. 2014 [cited 2019 Mei 13];20(1):24-32.

13. Kementerian Kesehatan R. Profil Kesehatan Indonesia Tahun 2017. 2017 [cited 2019 Mei 13]; Available from: http:// www.depkes.go.id/resources/download/pusdatin/profilkesehatan indonesia/Profil-Kesehatan-Indonesia-2017.pdf

14. Hunegnaw MT, Gezie LD, Teferra AS. Exclusive breastfeeding and associated factors among mothers in Gozamin District, Northwest Ethiopia/ : a community based cross-sectional study. Int Breastfeed J. 2017 [cited 2019 Mei 13];1-8. Available from: https://doi.org.10.1186/ s13006-017-0121-1
15. Tan KL. Factors associated with exclusive breastfeeding among infants under six months of age in Peninsular Malaysia. Int Breastfeed J [Internet]. 2011 [cited 2019 Mei 13];6(1):2. Available from: http:// www.internationalbreastfeedingjournal.com/content/6/1/ 2

16. Siregar A. Faktor Faktor yang Mempengaruhi Pemberian ASI oleh Ibu Melahirkan. 2004 [cited 2019 Mei 14]; Available from: http://library.usu.ac.id

17. Mihrshahi S, Kabir I, Roy SK, Agho KE, Senarath U. Determinants of infant and young child feeding practices in Bangladesh/: Secondary data analysis of Demographic and Health Survey 2004. 2010 [cited 2019 Oktober 13];31(2). Available from: http://journals.sagepub.com/ doi.pdf/10.1177/1564826510031002

18. Pandey S, Tiwari K, Senarath U, Agho KE, Dibley MJ. Determinants of infant and young child feeding practices in Nepal/: secondary data analysis of demographic and health survey 2006. 2010 [cited 2019 Oktober 13];31(2):334-51. Available from: http:// journals.sagepub.com/doi/pdf/10.1177/1564826510031

19. Adugna B, Tadele $H$, Reta $F$, Berhan $Y$. Determinants of exclusive breastfeeding in infants less than six months of age in hawassa, an urban setting, Ethiopia. International Breastfeeding Journal; 2017 [cited 2019 Oktober 13];411. Available from: https://ncbi.nlm.nih.gov/pmc/articles/ PMC5669024

20. Asemahagn MA. Determinants of exclusive breastfeeding practices among mothers in Azezo District, Northwest Ethiopia. Int Breastfeed J [Internet].; 2016 [cited 2019 Mei 13];1-7. Available from: http://dx.doi.org/10.1186/s13006016-0081-x

21. Lenja A, Demissie T, Yohannes B, Yohannis M. Determinants of exclusive breastfeeding practice to infants aged less than six months in Offa District, Southern Ethiopia/ :a cross-sectional study. Int Breastfeed J [Internet]. 2016 [cited 2019 Mei 13];1-7. Available from: http://dx.doi.org/ 10.1186/s13006-016-0091-8

22. Woldie TG, Kassa AW, Edris M. Assessment of exclusive breast feeding practice and associated factors in Mecha District, North West Ethiopia. Sci J Public Health. 2014 [cited 2019 Mei 13];2(4):330-6. Available from: http:// 10.11648.j.sjph.20140204.24

23. Tadesse T, Mesfin F, Chane T. Prevalence and associated factors of non- exclusive breastfeeding of infants during the first six months in rural area of Sorro District, Southern Ethiopia/ : a cross-sectional study. Int Breastfeed J [Internet].2016 [cited 2019 Mei 13];1-8. Available from: http://dx.doi.org/10.1186/s13006-016-0085-6

24. Tampah-naah AM, Kumi-kyereme A. Determinants of Exclusive Breastfeeding among Mothers in Ghana/: A Cross-sectional Study. Int Breastfeed J [Internet]. 2013 [cited 2019 Mei 13];8(1):1. Available from: https:// ncbi.nlm.nih.gov/pubmed/24119727 
Jurnal Epidemiologi Kesehatan Indonesia Vol. 3, No. 2, Desember 2019 